\title{
H. pylori May Not Be Associated with Iron Deficiency Anemia in Patients with Normal Gastrointestinal Tract Endoscopy Results
}

\author{
Tayyibe Saler, ${ }^{1}$ Şakir Özgür Keşkek, ${ }^{2}$ Sibel Kırk, ${ }^{1}$ Süileyman Ahbab, ${ }^{3}$ and Gülay Ortoğlu ${ }^{2}$ \\ ${ }^{1}$ Department of Internal Medicine, Umraniye Training and Research Hospital, 34767 Istanbul, Turkey \\ ${ }^{2}$ Department of Internal Medicine, Numune Training and Research Hospital, Yüreğir, 01240 Adana, Turkey \\ ${ }^{3}$ Department of Internal Medicine, Haseki Training and Research Hospital, 34087 Istanbul, Turkey \\ Correspondence should be addressed to Şakir Özgür Keşkek; drkeskek@yahoo.com
}

Received 21 July 2014; Revised 1 December 2014; Accepted 17 December 2014; Published 31 December 2014

Academic Editor: Andreas Neubauer

Copyright (C) 2014 Tayyibe Saler et al. This is an open access article distributed under the Creative Commons Attribution License, which permits unrestricted use, distribution, and reproduction in any medium, provided the original work is properly cited.

\begin{abstract}
Background. The aim of this study was to investigate the association between iron deficiency anemia and $H$. pylori in patients with normal gastrointestinal tract endoscopy results. Materials and Methods. A total of 117 male patients with normal gastrointestinal tract endoscopy results were included in this retrospective study. The study and control groups included 69 and 48 patients with and without iron deficiency anemia, respectively. The prevalence of $H$. pylori, the number of RBCs, and the levels of HGB, HTC, $\mathrm{MCV}$, iron, and ferritin were calculated and compared. Results. There was no statistically significant difference found between the groups according to the prevalence of $H$. pylori (65.2\% versus $64.6 \%, P=0.896)$. Additionally, the levels of RBCs, HGB, HTC, $\mathrm{MCV}$, iron, and ferritin in the patients in the study group were lower than those in the control group $(P<0.05)$. Finally, there was no association between iron deficiency anemia and $H$. pylori (OR 1.02, $\mathrm{Cl} 95 \% 0.47-2.22$, and $P=0.943$ ). Conclusion. H. pylori is not associated with iron deficiency anemia in male patients with normal gastrointestinal tract endoscopy results.
\end{abstract}

\section{Introduction}

Anemia is the most common disorder of the blood and is characterized by a decrease in the number of red blood cells or a less-than-normal quantity of hemoglobin in the blood. The hemoglobin value below which anemia is defined varies, although the World Health Organization (WHO) hemoglobin thresholds of less than $13 \mathrm{~g} / \mathrm{dL}$ for men and less than $12 \mathrm{~g} / \mathrm{dL}$ for women [1] are the most common definitions used for anemia.

Iron deficiency anemia is the most common form of anemia worldwide. It is a global public health problem affecting both developing and developed countries, with major consequences for human health as well as social and economic development. The causes of iron deficiency anemia include inadequate iron intake, chronic blood loss, and impaired iron absorption. Blood loss from the gastrointestinal tract is the most common cause in men and postmenopausal women $[2,3]$.

Helicobacter pylori is a Gram-negative bacterium that colonizes human gastric mucosa, leading to chronic antral gastritis and peptic ulcer disease. It is also associated with serious diseases, including gastric cancer and gastric mucosaassociated lymphoid tissue lymphoma. H. pylori remains one of the most common infections in the world, with an estimated $50 \%$ of the world's population being carriers of the bacterium $[4,5]$.

Previous studies have shown that $H$. pylori colonization of the gastric mucosa may impair iron uptake and increase iron loss, potentially leading to iron deficiency anemia [6, 7]. There have been no studies performed in patients with intact gastric mucosa. Therefore, in this study we aimed to investigate the association between $H$. pylori and iron deficiency anemia in patients with normal gastrointestinal tract endoscopy results.

\section{Materials and Methods}

For this study, a total of 1251 patient files were analysed. There were 906 patients with sufficient data for this study, but patients with chronic diseases, under 18 years old, diagnosed 
TABLE 1: Characteristics of the study and control groups.

\begin{tabular}{lccc}
\hline & $\begin{array}{c}\text { Study group } \\
(N=69)\end{array}$ & $\begin{array}{c}\text { Control group } \\
(N=48)\end{array}$ & $P$ \\
\hline Age (years) & $37.4 \pm 10.4$ & $40.2 \pm 10.0$ & 0.143 \\
H. pylori $N(\%)$ & $45(65.2 \%)$ & $31(64.6 \%)$ & 0.896 \\
RBC $\left(4.2-5.1 \times 10^{6} / \mathrm{uL}\right)$ & $3.84 \pm 0.36$ & $4.69 \pm 0.38$ & $<0.001$ \\
Hemoglobin & $9.6 \pm 1.3$ & $13.4 \pm 0.97$ & $<0.001$ \\
$(12-15$ gr/dL) & $31.9 \pm 3.3$ & $40.5 \pm 2.7$ & $<0.001$ \\
HTC $(\%)$ & $71.5 \pm 5.8$ & $85.9 \pm 6.2$ & $<0.001$ \\
MCV $(80-96 \mathrm{fl})$ & $26.1 \pm 12$ & $74 \pm 27$ & $<0.001$ \\
Iron $(37-145 \mu \mathrm{g} / \mathrm{dL})$ & $5.4 \pm 2.8$ & $66.7 \pm 51.9$ & $<0.001$ \\
Ferritin $(13-150 \mathrm{ng} / \mathrm{mL})$ & & &
\end{tabular}

with anemia other than iron deficiency anemia, abnormal gastrointestinal tract endoscopy results, malignancies, parasitosis, positive fecal occult blood tests, and those taking medications that affect $H$. pylori, blood levels, or iron levels, as well as females, were excluded. Finally, 117 male patients with normal gastrointestinal tract endoscopy results were included in this study. The study group consisted of 69 patients with iron deficiency anemia, and the control group consisted of 48 patients without anemia. Females were excluded due to a high prevalence of anemia due to other causes, such as menstruation.

Iron deficiency anemia was defined according to the World Health Organization (WHO) criteria [1], which define anemia as a hemoglobin level of $<13 \mathrm{~g} / \mathrm{dL}$ in men and $<12 \mathrm{~g} / \mathrm{dL}$ in women. The definition of iron deficiency anemia was accepted as being when the serum iron was $<37 \mu \mathrm{g} / \mathrm{dL}$ and ferritin was $<13 \mathrm{ng} / \mathrm{mL}$. The complete blood counts, serum iron levels, and ferritin concentrations of all of the patients were reported, and the peripheral blood samples were evaluated. Additionally, the complete blood counts were measured using the Sysmex XE 2100i (Japan) by fluorescence flow cytometry. The serum iron levels and ferritin concentrations were measured with the Roche C-601 analyser tract (Japan) using an electrochemiluminescence immunoassay at the institute. A Fujinon EG-590 WR HD (Saitama, Japan) model device was used for the gastrointestinal tract endoscopy procedures (esophagogastroduodenoscopy and colonoscopy) in those years at the institute.

Biopsy samples taken from the antrum during the operation were evaluated after being stained with PAS-AB or modified Giemsa by an experienced pathologist. According to the patient files, we reported that the analyses of $H$. pylori were made via histological examination and the rapid urease test (CLO test: Campylobacter-like organism test). According to the CLO test (Delta West Bentley, WA, Australia), the change in the colour of the test from yellow to red was accepted as a positive result [8]. The prevalence of $H$. pylori infections, the number of RBCs, and the levels of HGB, HTC, $\mathrm{MCV}$, iron, and ferritin were calculated and compared in both groups.

MedCalc 12.7 software program (MedCalc Belgium) was used for statistical analysis. Categorical measurements were
TABLE 2: Measurements of patients in study group according to the Helicobacter pylori infection.

\begin{tabular}{lccc}
\hline & $\begin{array}{c}\text { H. pylori }(+) \\
(N=45)\end{array}$ & $\begin{array}{c}\text { H. pylori }(-) \\
(N=24)\end{array}$ & $P$ \\
\hline RBC $\left(4.2-5.1 \times 10^{6} / \mathrm{uL}\right)$ & $3.89 \pm 0.37$ & $4.00 \pm 0.35$ & 0.234 \\
Hemoglobin & $9.5 \pm 1.4$ & $9.8 \pm 1.2$ & 0.466 \\
$(12-15 \mathrm{gr} / \mathrm{dL})$ & $31.5 \pm 3.4$ & $32.5 \pm 3.0$ & 0.261 \\
HTC $(\%)$ & $71.2 \pm 6.1$ & $72.1 \pm 5.2$ & 0.546 \\
MCV $(80-96 \mathrm{fl})$ & $26.6 \pm 13.7$ & $25.0 \pm 8.2$ & 0.584 \\
Iron $(37-145 \mu \mathrm{g} / \mathrm{dL})$ & $5.5 \pm 2.5$ & $5.2 \pm 3.2$ & 0.439 \\
Ferritin $(13-150 \mathrm{ng} / \mathrm{mL})$ & & & \\
\hline
\end{tabular}

reported as number and percentage. Quantitative measurements were reported as the mean \pm SD (Standard Deviation). Kolmogorov-Smirnov test was used to show the normal distribution of quantitative measurements. Chi square test was used to compare categorical measures and frequency of metabolic syndrome between the groups. $t$-test or MannWhitney $U$ tests were used for comparison of quantitative measurements between the two groups. An odds ratio was used to analyse the degree of association between $H$. pylori and iron deficiency anemia. The level of statistical significance was set as 0.05 in all tests.

\section{Results}

The characteristics of the groups are shown in Table 1, and the mean ages are comparable in both groups: $37.4 \pm 10.4$ and $40.2 \pm 10.0$ in the study and control groups, respectively $(P=0.143)$. There was no statistically significant difference between the groups according to the prevalence of $H$. pylori (65.2\% versus $64.6 \%$, resp.; $P=0.896)$. Not surprisingly, the RBC, HGB, HTC, MCV, iron, and ferritin levels of the patients in the study group were lower than those in the control group. There were no statistically significant differences between the RBC, HGB, HTC, MCV, iron, and ferritin levels in the patients with or without $H$. pylori infections according to the presence or absence of iron deficiency anemia $(P>0.05$; Tables 2 and 3). When we mixed the patients (anemic and nonanemic) and divided them according to the $H$. pylori infections, we saw that there was no statistically significant difference $(P>0.05$; Table 4$)$. Finally, there was no association between iron deficiency anemia and $H$. pylori (OR 1.02, Cl 95\% 0.47-2.22, $P=0.943$ ).

\section{Discussion}

In this study, we have shown that $H$. pylori is not associated with iron deficiency anemia in men with normal gastrointestinal tract endoscopy results. Iron deficiency anemia is a common health problem in the general population $[1$, 2]. Similarly, $H$. pylori is a common gastrointestinal tract infection that affects a majority of the population. Guidelines on iron deficiency anemia have confirmed the etiological role of H. pylori, but the relationship remains controversial. Some previous studies have reported that $H$. pylori is associated 
TABLE 3: Measurements of patients in control group according to the Helicobacter pylori infection.

\begin{tabular}{lccc}
\hline & $\begin{array}{c}\text { H. pylori }(+) \\
N=31\end{array}$ & $\begin{array}{c}\text { H. pylori }(-) \\
N=17\end{array}$ & $P$ \\
\hline RBC $\left(4.2-5.1 \times 10^{6} / \mathrm{uL}\right)$ & $4.7 \pm 0.35$ & $4.59 \pm 0.44$ & 0.351 \\
Hemoglobin & $13.5 \pm 0.97$ & $13.3 \pm 0.97$ & 0.402 \\
$(12-15 \mathrm{gr} / \mathrm{dL})$ & $40.7 \pm 2.6$ & $40.2 \pm 2.9$ & 0.535 \\
HTC $(\%)$ & $86.0 \pm 6.6$ & $85.9 \pm 5.7$ & 0.959 \\
MCV $(80-96 \mathrm{fl})$ & $73.9 \pm 30.5$ & $75.7 \pm 22.5$ & 0.830 \\
Iron $(37-145 \mu \mathrm{g} / \mathrm{dL})$ & $59.7 \pm 43.7$ & $79.4 \pm 63.8$ & 0.213 \\
Ferritin $(13-150 \mathrm{ng} / \mathrm{mL})$ & & & \\
\hline
\end{tabular}

with iron deficiency anemia; since $H$. pylori colonization in the gastric mucosa may disturb some functions of the mucosa, it leads to a decrease in iron absorption and increases iron loss $[6,7]$. This is an excellent description for the results reported in these studies; however, these results may be acceptable only for patients with abnormal gastrointestinal tract endoscopy.

According to our opinion, iron deficiency anemia and H. pylori infections may be a coincidence because both of the diseases are highly prevalent. Moreover, there are many causes that lead to iron deficiency anemia, such as malnutrition, vitamin deficiencies, chronic disorders, infections, and conditions associated with chronic blood loss $[9,10]$. Therefore, we planned our study in patients with normal gastrointestinal tract endoscopy results and found no association. Furthermore, we have shown no difference between the RBC, HGB, HTC, MCV, iron, and ferritin levels in the patients with or without $H$. pylori infections in both groups. To our knowledge, this is the first study that investigates the association between iron deficiency anemia and $H$. pylori in patients with normal gastrointestinal tract endoscopy. Male gender in this study may constitute a bias; however, we planned this study with males because women have greater risks for iron deficiency anemia and the majority of them are due to menstruation bleeding. Consequently, we could develop incorrect results if we included women in this study.

According to the literature, there are some studies which have shown the benefits of $H$. pylori treatment on iron deficiency anemia. For example, improved iron deficiency was reported after the eradication of $H$. pylori $[11,12]$. In Malik et al's study, they have shown that the eradication of $H$. pylori resulted in a significantly better response to oral iron supplementation among $H$. pylori infected pregnant women with iron deficiency anemia [11]. Nevertheless, gastrointestinal endoscopy was not performed in this study; additionally, antiulcer treatment was given to the patients in the study group. In another study, Huang et al. reported that H. pylori eradication therapy combined with iron administration is more effective than iron administration alone for the treatment of iron deficiency anemia [12]. They also stated that bismuth based triple therapy has a better response in terms of increased hemoglobin and serum ferritin concentrations
TABLE 4: Measurements of patients according to the Helicobacter pylori infection.

\begin{tabular}{lccc}
\hline & $\begin{array}{c}\text { H. pylori }(+) \\
N=76\end{array}$ & $\begin{array}{c}\text { H. pylori }(-) \\
N=41\end{array}$ & $P$ \\
\hline RBC $\left(4.2-5.1 \times 10^{6} / \mathrm{uL}\right)$ & $4.2 \pm 0.54$ & $4.2 \pm 0.46$ & 0.803 \\
Hemoglobin & $11.1 \pm 2.3$ & $11.2 \pm 2.0$ & 0.863 \\
$(12-15$ gr/dL $)$ & $35.3 \pm 5.5$ & $35.7 \pm 4.8$ & 0.695 \\
HTC $(\%)$ & $77.2 \pm 9.6$ & $77.8 \pm 8.7$ & 0.747 \\
MCV $(80-96 \mathrm{fL})$ & $45.9 \pm 32.1$ & $46.0 \pm 29.7$ & 0.788 \\
Iron $(37-145 \mu \mathrm{g} / \mathrm{dL})$ & $27.6 \pm 38.5$ & $36.0 \pm 54.8$ & 0.949 \\
Ferritin $(13-150 \mathrm{ng} / \mathrm{mL})$ & & &
\end{tabular}

than proton pump inhibitor based triple therapy. It is understood that all patients in their study had gastrointestinal problems because they were given bismuth or a proton pump inhibitor based triple therapy. In such cases, iron deficiency anemia is an expected condition due to the impaired mucosa, but in our study all patients had intact mucosa.

Hsiang-Yao et al. studied 882 patients in Taiwan and showed no significant association between chronic $H$. pylori infections and anemia. The sample size of their study was larger, but they did not exclude most of the concomitant conditions. Moreover, gastrointestinal system endoscopy was not performed for all of the patients [13]. Qu et al. performed a meta-analysis of observational studies and randomized controlled trials, and they concluded that iron deficiency anemia could not specifically be related to $H$. pylori infections. Moreover, they did not recommend a strategy of populationbased screening and treatment for $H$. pylori infections to prevent iron deficiency anemia [14].

In the present study, iron deficiency in patients with normal gastrointestinal system endoscopy results may be associated with lifestyle, for example, inadequate or improper nutrition and excessive drinking of tea and/or coffee.

The small sample size is a limitation in this study; however, a total of 1251 patient files were analysed at the baseline. We excluded most of the patients due to the wide exclusion criteria, although the wide exclusion criteria may be a strong point for this study.

In conclusion, we can say that $H$. pylori is not associated with iron deficiency anemia in men with normal gastrointestinal tract endoscopy results. However, H. pylori may be associated with iron deficiency anemia in patients with impaired gastrointestinal mucosa.

\section{Conflict of Interests}

The authors declare that there is no conflict of interests regarding the publication of this paper.

\section{Authors' Contribution}

Tayyibe Saler A, B, D, Şakir Özgür Keşkek C, E, D, F, Sibel Kırk B, Süleyman Ahbab B, Gülay Ortoğlu D. 


\section{References}

[1] World Health Organization, Worldwide Prevalence of Anemia 1993-2005: WHO Global Database on Anemia, World Health Organization, Geneva, Switzerland, 2008.

[2] U. D. Bayraktar and S. Bayraktar, "Treatment of iron deficiency anemia associated with gastrointestinal tract diseases," World Journal of Gastroenterology, vol. 16, no. 22, pp. 2720-2725, 2010.

[3] N. D. Goldberg, "Iron deficiency anemia in patients with inflammatory bowel disease," Clinical and Experimental Gastroenterology, vol. 6, pp. 61-70, 2013.

[4] J. G. Kusters, A. H. M. Van Vliet, and E. J. Kuipers, "Pathogenesis of Helicobacter pylori infection," Clinical Microbiology Reviews, vol. 19, no. 3, pp. 449-490, 2006.

[5] A. Sethi, M. Chaudhuri, L. Kelly, and W. Hopman, "Prevalence of Helicobacter pylori in a first nations population in Northwestern Ontario," Canadian Family Physician, vol. 59, no. 4, pp. e182-e187, 2013.

[6] H. Monzón, M. Forné, M. Esteve et al., "Helicobacter pylori infection as a cause of iron deficiency anaemia of unknown origin," World Journal of Gastroenterology, vol. 19, no. 26, pp. 4166-4171, 2013.

[7] K. Muhsen and D. Cohen, "Helicobacter pylori infection and iron stores: a systematic review and meta-analysis," Helicobacter, vol. 13, no. 5, pp. 323-340, 2008.

[8] L. A. Laine, R. A. Nathwani, and W. Naritoku, "The effect of GI bleeding on Helicobacter pylori diagnostic testing: a prospective study at the time of bleeding and 1 month later," Gastrointestinal Endoscopy, vol. 62, no. 6, pp. 853-859, 2005.

[9] L. E. Damon, C. Andreadis, and C. A. Linker, Blood Disorders: Current Medical Diagnosis and Treatment, McGraw-Hill, New York, NY, USA, 52nd edition, 2014.

[10] J. W. Adamson, "Iron deficiency and other hypoproliferative anemias," in Harrison's Principles of Internal Medicine, D. L. Longo, A. S. Fauci, D. L. Kasper, S. L. Hauser, J. L. Jameson, and J. Loscalzo, Eds., pp. 844-851, McGraw-Hill, New York, NY, USA, 18th edition, 2012.

[11] R. Malik, K. Guleria, I. Kaur, M. Sikka, and G. Radhakrishnan, "Effect of Helicobacter pylori eradication therapy in iron deficiency anaemia of pregnancy-a pilot study," Indian Journal of Medical Research, vol. 134, no. 8, pp. 224-231, 2011.

[12] X. Huang, X. Qu, W. Yan et al., "Iron deficiency anaemia can be improved after eradication of Helicobacter pylori," Postgraduate Medical Journal, vol. 86, no. 1015, pp. 272-278, 2010.

[13] S. Hsiang-Yao, K. Fu-Chen, S. Sophie et al., "Helicobacter pylori infection and anemia in Taiwanese adults," Gastroenterology Research and Practice, vol. 2013, Article ID 390967, 4 pages, 2013.

[14] X.-H. Qu, X.-L. Huang, P. Xiong et al., "Does Helicobacter pylori infection play a role in iron deficiency anemia? A metaanalysis," World Journal of Gastroenterology, vol. 16, no. 7, pp. 886-896, 2010. 


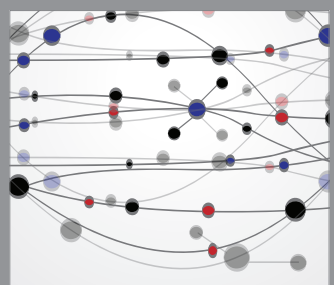

The Scientific World Journal
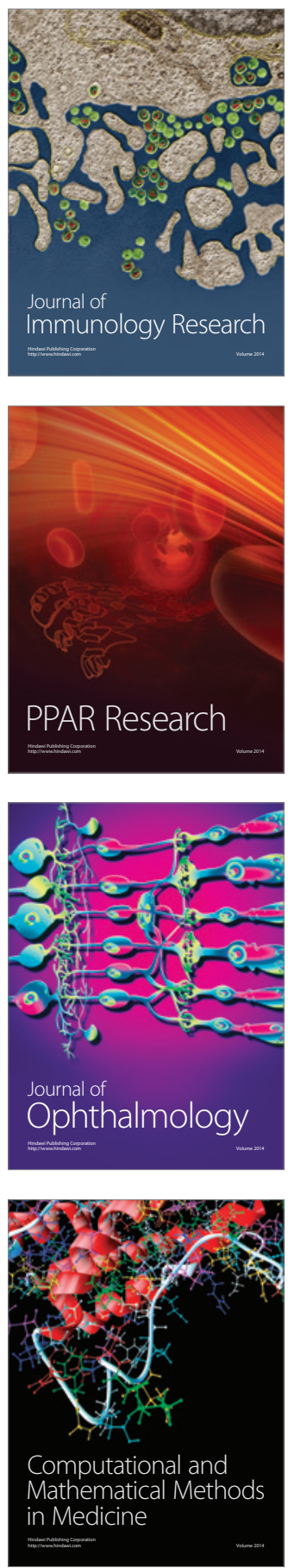

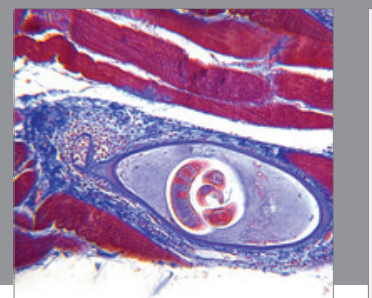

Gastroenterology

Research and Practice
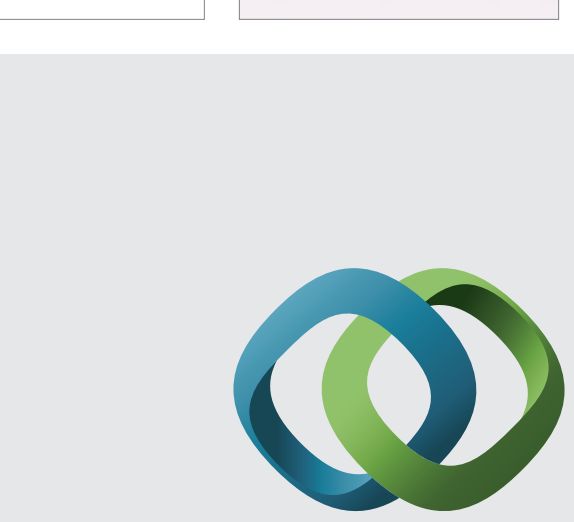

\section{Hindawi}

Submit your manuscripts at

http://www.hindawi.com
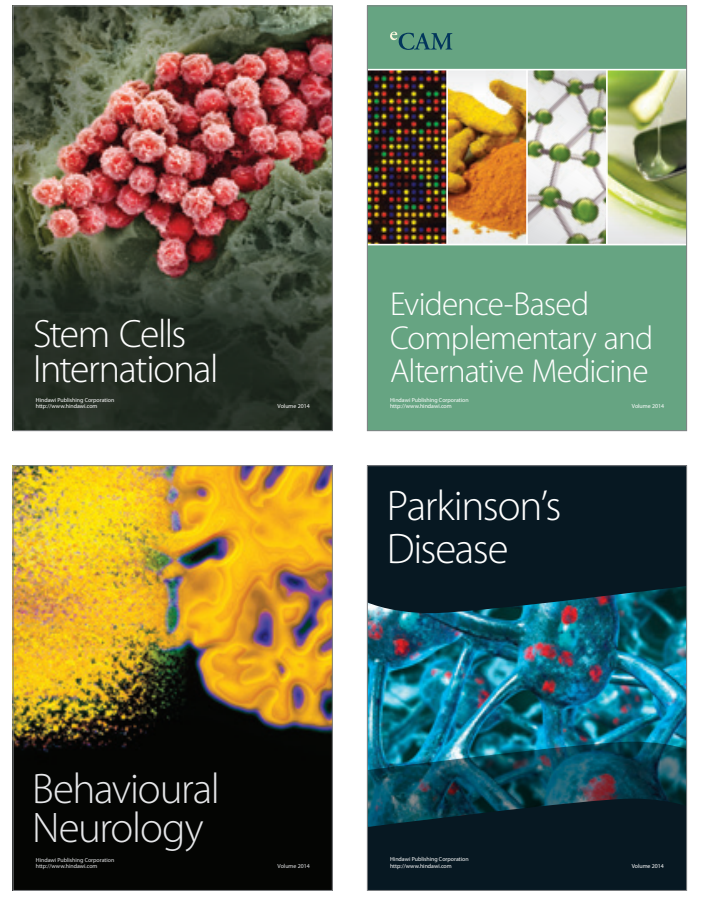
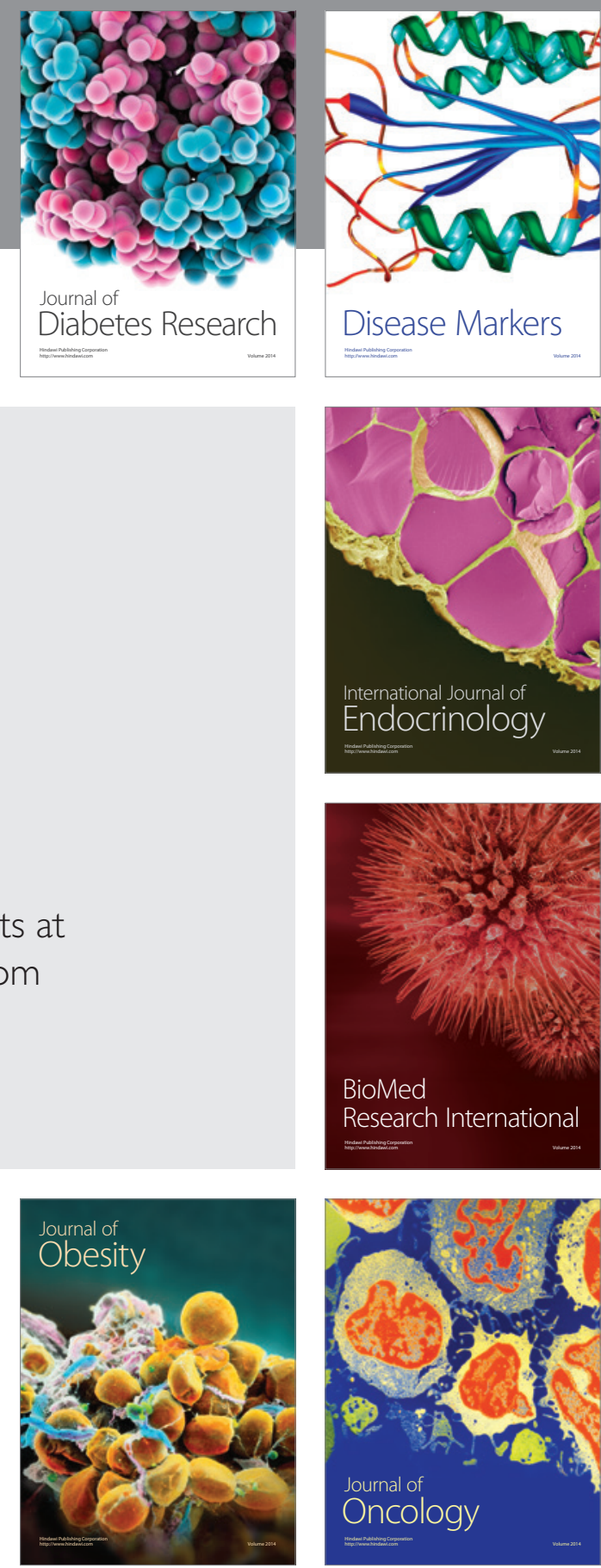

Disease Markers
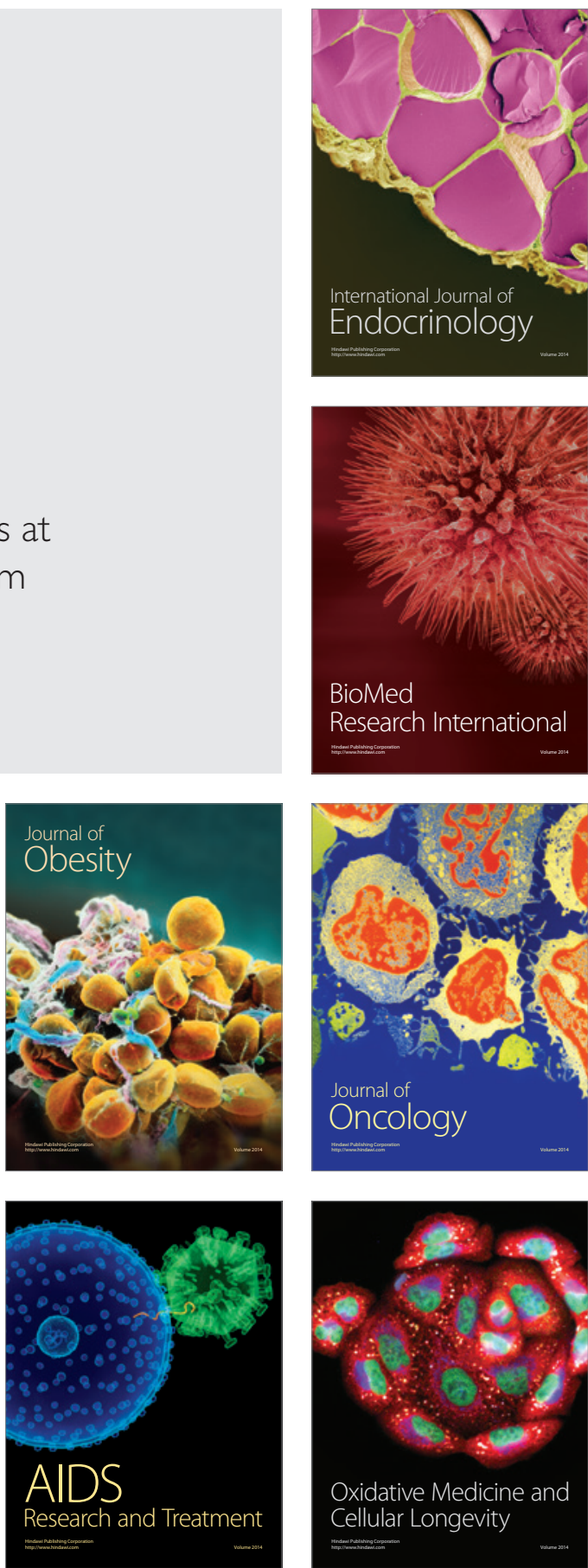